\title{
Pengaruh Variasi Temperatur Terhadap Kinetika Reaksi Solidifikasi Fly Ash Paving Blok Geopolimer
}

\author{
Aman $^{1}$, Amir Awaluddin', Adrianto Ahmad ${ }^{3}$, Monita Olivia $^{4}$ \\ 1,3, Jurusan Teknik Kimia Fakultas Teknik Universitas Riau \\ ${ }^{4}$ Jurusan Teknik Sipil Fakultas Teknik Universitas Riau \\ 2 Jurusan Kimia Fakultas MIPA Universitas Riau
}

\begin{abstract}
This paper reported about the investigated of fly ash solidification with geopolymer process that studied temperature variation on the rate of solidification using Vicat Nidle apparatus and leaching tests on the content of heavy metals $\mathrm{Cu}, \mathrm{Pb}, \mathrm{Cr}$ and $\mathrm{Cd}$ in paving blocks after solidification. The transformation process of geopolymer crystalline formation was analyzed by Avrami's kinetics theory (Avrami's kinetica theory). From the results of the study obtained the optimum temperature of $80{ }^{\circ} \mathrm{C}$, the highest rate of crystal growth solidification $(K)$ value of 0.0475 and the Avrami exponent value (n) of 2.310 in this geopolymerization process shows a two-dimensional structure. From the results of leaching levels of heavy metals $\mathrm{Cu}, \mathrm{Pb}, \mathrm{Cr}$ and $\mathrm{Cd}$ in fly ash paving blocks are very small degraded in water and still below the environmental threshold.
\end{abstract}

Key words: fly ash, geopolimer, kinetika, solidifikasi, leaching

Berdasarkan Peraturan Pemerintah (PP) No.101 tahun 2014 tentang pengelolaan limbah bahan berbahaya dan beracun (B3), fly ash dikategorikan sebagai limbah B3 karena terdapat kandungan oksida logam berat yang akan mengalami pelindihan secara alami dan mencemari lingkungan. Penanganan yang direkomendasikan oleh PP No.101 tahun 2014 adalah secara solidifikasi dimana dengan proses tersebut sifat B3 dalam fly ash akan menjadi stabil dan dapat dimanfaatkan sebagai produk yang aman bagi kesehatan dan lingkungan.

Metode solidifikasi dalam penanganan limbah fly ash yang telah dilakukan selama ini diantaranya fly ash digunakan sebagai campuran semen pada beton karena mempunyai sifat pozzolanic (Wardani, 2008) sebagai bahan pengisi (filler) aspal beton, pada industri bata, genteng, batako dan lain sebagainya [Munir, 2008; Utama, 2004; Pratomo, 2001 dan Safitri, 1998].

Adapun metode solidifikasi dalam penelitian ini adalah dengan proses geopolimer yang bersih dan ramah lingkungan. Geopolimer dihasilkan melalui reaksi padatan aluminosilikat yang terdapat dalam material fly ash dengan aktivator basa kuat menghasilkan binder/perekat seperti semen.
Pembuatan material geopolimer menggunakan bahan yang banyak mengandung unsur-unsur silika dan alumina. Unsur-unsur tersebut banyak ditemukan pada material buangan hasil samping industri, seperti fly ash dan slag. Beton atau paving blok geopolimer memberikan keuntungan dalam hal pemanfaatan limbah hasil buangan pabrik sebagai bahan yang dapat digunakan, meskipun perbedaan tempat asal sumber material berpengaruh terhadap perbedaan hasil kekuatan beton/paving blok (Olivia, 2011).

Peneliti terdahulu mengenai geopolimer fokus mempelajari sifat-sifat mekanik material seperti kuat tekan, kuat tarik, kuat lentur dan porositas beton atau paving blok geopolimer, akan tetapi kajian mengenai kinetika reaksi solidifikasi dan pelindian (leaching) logam berat dalam material paving blok masih belum banyak dilakukan sementara referensi mengenai kinetika reaksi dalam proses geopolimer sangat penting diketahui agar dapat dipelajari berapa kecepatan reaksi dan waktu yang dibutuhkan oleh material untuk mencapai kondisi / fase kristal atau kekerasan yang diharapkan, selanjutnya juga bagaimana kandungan logam berat yang ada didalam material apakah terimobilisasi kuat dengan komponen lain yang 
ada didalam struktur bangunnya setelah dilakukan uji pelindian.

\section{BAHAN DAN METODE}

Penelitian ini menggunakan fly ash dari PT.RAPP kabupaten Pelalawan provinsi Riau, Larutan Natrium Hidroksida $(\mathrm{NaOH})$ dari gudang bahan kimia Jurusan Teknik Kimia FT UR, Natrium Silikat $\left(\mathrm{Na}_{2} \mathrm{SiO}_{3}\right)$ berupa larutan dibeli dari PT. Sinar Sakti Kimia Solo, Air dari laboratorium Teknik Reaksi Kimia Jurusan Teknik Kimia FT UR. Agregat halus/pasir dari Quarry Rimbo Panjang Kabupaten Kampar, Riau. Peralatan yang digunakan timbangan, gelas ukur, piknometer, mesin pencetak paving blok milik CV. Rangga Beton, Compression Testing Machine untuk uji kuat tekan paving blok di laboratorium Teknologi Bahan Jurusan Teknik Sipil FT-UR.

Adapun prosedur kerja penelitian untuk kinetika reaksi solidifikasi dalam air sebagai berikut : Preparasi larutan aktivator konsentrasi NaOH $14 \mathrm{M}$ sampel (M16) dengan rasio liquid aktivator to solid fly ash (L/S) 0,5 dan rasio fly ash to aggregat pasir (1:3) dan temperatur perawatan $80^{\circ} \mathrm{C}$. Kemudian campurkan larutan aktivator, fly ash dan agregate sampai homogen, setelah itu lakukan proses moulding dengan variasi temperatur ruang (30), 60, 80, dan $100{ }^{\circ} \mathrm{C}$. Selanjutnya dilakukan pengujian kekerasan atau solidifikasi dengan alat Vicat Needl dan dicatat hasil yang didapat untuk masing-masing temperatur. Pejelasan / analisa hasil yang didapat menggunakan Teori Kinetika Avramy (Avrami's kinetic theory).

\section{Uji Pelindian (leaching)}

Selanjutnya uji pelindian (leaching) sebagai berikut : Material paving blok kode M16 direndam dalam bejana yang berisi air selama 28 hari . Setiap hari ke 3, 6, 9, 12, 15, 18, 21, 24, dan 28 diambil airnya dan dianalisa kandungan logam berat $(\mathrm{Cu}, \mathrm{Cd}, \mathrm{Cr}$ dan $\mathrm{Pb})$ dengan alat Atomic Absorption Spectroscopy (AAS). Data yang diperoleh selanjutnya dianalisa dan dikomparasi dengan standar baku mutu yang diperbolehkan oleh lingkungan.

\section{HASIL}

Dari hasil eksperimen, variasi suhu perawatan (curing) dengan konsentrasi aktivator yang optimum $14 \mathrm{M} \mathrm{NaOH}$ menghasilkan waktu yang lebih pendek untuk setiap kenaikan temperatur pada proses pemadatan (solidifikasi) geopolimer. Selanjutnya dari Teori Kinetic Avrami's, bentuk pertumbuhan kristal dalam proses geopolimerisasi menunjukkan struktur dua dimensi sementara sampel tertentu dari geopolimer menunjukkan adanya nukleasi sekunder dalam pertumbuhan geopolimer.

\section{Variasi Temperatur terhadap laju solidifikasi}

Pada Gambar 1 di bawah menunjukkan hubungan antara variasi temperatur terhadap laju solidifikasi geopolimer pada konsentrasi 14 $\mathrm{M} \mathrm{NaOH}$.

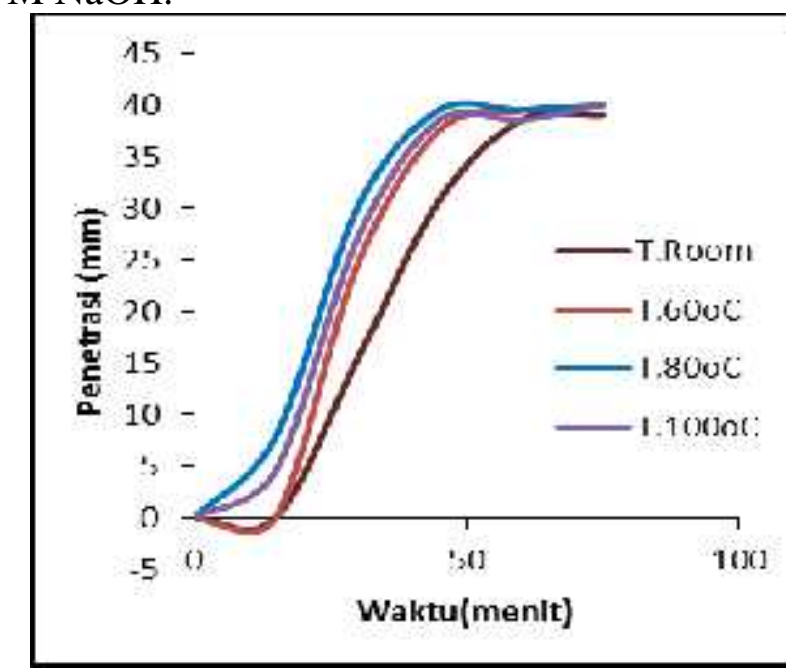

Gambar 1. Variasi Temperatur terhadap laju solidifikasi pada $\mathrm{NaOH} 14 \mathrm{M}$

\section{Teori Kinetika Avrami's (Avrami's Kinetica} Teory)

Gambar 2. di bawah menampilkan efek temperatur pada konsentrasi optimum $\mathrm{NaOH} 14$ M pada solidifikasi geopolimer. 


\begin{tabular}{|c|c|c|c|c|}
\hline \multirow{2}{*}{$\begin{array}{l}\text { Hari } \\
\text { Ke- }\end{array}$} & \multicolumn{4}{|c|}{ Mix Design M16 } \\
\hline & $\begin{array}{c}\mathrm{Cu} \\
(\mathrm{mg} / \mathrm{L})\end{array}$ & $\begin{array}{c}\mathrm{Cd} \\
(\mathrm{mg} / \mathrm{L}) \\
\end{array}$ & $\begin{array}{c}\mathrm{Cr} \\
(\mathrm{mg} / \mathrm{L})\end{array}$ & $\begin{array}{c}\mathrm{Pb} \\
(\mathrm{mg} / \mathrm{L}) \\
\end{array}$ \\
\hline 0 & 0,000 & 0,000 & $\operatorname{ttd}$ & 0,000 \\
\hline 3 & 0,032 & 0,011 & $\operatorname{ttd}$ & 0,01 \\
\hline 6 & 0,033 & 0,014 & $\operatorname{ttd}$ & 0,02 \\
\hline 9 & 0,035 & 0,019 & $\operatorname{ttd}$ & 0,03 \\
\hline 12 & 0,038 & 0,026 & $\operatorname{ttd}$ & 0,09 \\
\hline 15 & 0,039 & 0,033 & $\mathrm{ttd}$ & 0,14 \\
\hline 18 & 0,039 & 0,046 & $\mathrm{ttd}$ & 0,19 \\
\hline 21 & 0,040 & 0,058 & $\operatorname{ttd}$ & 0,47 \\
\hline 24 & 0,042 & 0,061 & $\operatorname{ttd}$ & 0,68 \\
\hline 27 & 0,042 & 0,072 & $\mathrm{ttd}$ & 0,76 \\
\hline 28 & $\mathbf{0 , 0 4 2}$ & $\mathbf{0 , 0 7 2}$ & ttd & $\mathbf{0 , 7 6}$ \\
\hline $\begin{array}{c}\text { PP. } \\
\text { No.82/200 } \\
\text { Kelas IV }\end{array}$ & 0,2 & $\mathbf{0 , 0 1}$ & $\mathbf{0 , 0 1}$ & 1,0 \\
\hline 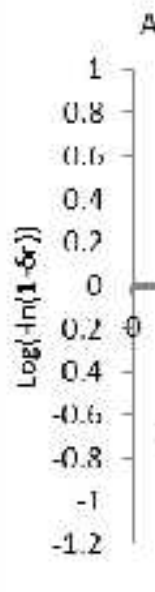 & $\begin{array}{c}0.5 \\
y=2.3102 x \\
R^{2}=0.958\end{array}$ & $\begin{array}{l}1 \\
\log \langle t\rangle\end{array}$ & $\begin{array}{l}2.5797 x- \\
R^{2}-0.7\end{array}$ & $\begin{array}{l}0.6163 \\
2\end{array}$ \\
\hline
\end{tabular}

Gambar 2. Avram's Plot terhadap perbedaan Temperatur

Tabel 1. Avrami's Exponent untuk Variasi Temperatur, $14 \mathrm{M} \mathrm{NaOH}$

\begin{tabular}{ccc}
\hline $\begin{array}{c}\text { Temperatur } \\
\left({ }^{\circ} \mathrm{C}\right)\end{array}$ & $\begin{array}{c}\text { Eksponen } \\
\text { Avrami }(\mathrm{n})\end{array}$ & $\begin{array}{c}\text { Growth Rate } \\
(\mathrm{K}),\left(\mathrm{min}^{-1)}\right.\end{array}$ \\
\hline T.room & 0,959 & $4,76 \times 10^{-5}$ \\
60 & 1,066 & $4,45 \times 10^{-4}$ \\
80 & 2,310 & $4,75 \times 10^{-2}$ \\
100 & 2,529 & $1,56 \times 10^{-2}$ \\
\hline
\end{tabular}

\section{Pelindian (Leaching) Kandungan Logam Berat}

Pelindian adalah untuk mengetahui tingkat immobilisasi logam berat pada limbah fly ash baik sebelum atau sesudah dilakukan solidifikasi . Oleh karena itu kandungan logam berat dalam abu terbang sebelum digunakan untuk pembuatan paving blok dianalisa terlebih dulu dengan AAS begitu juga hasil dari uji pelindiannya (leaching) seperti pada Tabel 2 di bawah.

Tabel 2. Kandungan logam berat dalam fly ash Vs M16

\begin{tabular}{cccc}
\hline No & Parameter & $\begin{array}{c}\text { Fly ash } \\
\text { Awal } \\
(\mathrm{mg} / \mathrm{L})\end{array}$ & $\begin{array}{c}\text { Mix } \\
\text { Design } \\
\text { M16 } \\
(\mathrm{mg} / \mathrm{L})\end{array}$ \\
\hline 1 & $\begin{array}{c}\text { Tembaga } \\
(\mathrm{Cu})\end{array}$ & 1,389 & 0,042 \\
2 & $\begin{array}{c}\text { Timbal } \\
(\mathrm{Pb})\end{array}$ & 1,72 & 0,76 \\
3 & $\begin{array}{c}\text { Krom }(\mathrm{Cr}) \\
\text { Kadmium } \\
(\mathrm{Cd})\end{array}$ & 0,538 & $\mathrm{ttd}$ \\
& 0,58 & 0,072 \\
\hline
\end{tabular}

Tabel 3. Hasil Uji pelindian kandungan logam berat paving blok

\section{PEMBAHASAN}

Dari Gambar 1 di atas sampel dengan temperatur $80^{\circ} \mathrm{C}$ mencapai pengerasan maksimum tercepat dibandingkan sampel dengan temperatur $100,60^{\circ} \mathrm{C}$ dan suhu ruang. Ini dapat dilihat dari waktu yang dibutuhkan sampel temperatur $80{ }^{\circ} \mathrm{C}$ selama 35 menit ,sedangkan temperatur $100{ }^{\circ} \mathrm{C}$ selama 40 menit. Sedangkan temperatur $60^{\circ} \mathrm{C}$ dan T.ruang samasama 60 menit. Hal ini disebabkan kecepatan penguapan air lebih cepat dengan bertambahnya waktu. Pada temperatur 80 dan $100{ }^{\circ} \mathrm{C}$ laju penguapan air lebih cepat dibandingkan temperatur $60^{\circ} \mathrm{C}$ dan temperatur ruang (room temperature), akan tetapi pada temperatur 100 ${ }^{\circ} \mathrm{C}$ produk geopolimer mengalami retak (cracking) sehingga mempengaruhi kuat tekan yang didapat. Hasil yang paling baik pada penelitian ini terjadi pada temperatur optimum $80{ }^{\circ} \mathrm{C}$ dengan kuat tekan tertinggi. Menurut (Wang dan Cheng, 2003) meningkatnya temperatur perawatan akan mempercepat proses geopolimerisasi ini disebabkan semakin berkurangnya kadar air didalam materal geopolimer yang berefek terhadap kuat tekan. Menurut Muniz-Villareal, (2010) menyatakan bahwa kuat tekan geopolimer sangat tergantung pada ukuran pori selama proses geopolimerisasi ini dipengaruhi oleh semakin tinggi temperatur jumlah pori material geopolimer semakin kecil, didapat temperatur yang optimum pada $80^{\circ} \mathrm{C}$.

Dari plot Avrami terhadap efek temperatur, nilai Avrami eksponen (n) dan konstanta laju pertumbuhan $(\mathrm{K})$ dirumuskan dan ditabulasikan pada Tabel 1. Berdasarkan Tabel 1 terlihat bahwa nilai Eksponen Avrami bervariasi dalam 
semua variasi temperatur yang diuji. Nilai ( $\mathbf{n}$ ) mulai dari 0,959 sampai 2,529 dimana $\mathbf{n}$ terkecil pada temperatur kamar sedangkan nilai (n) terbesar terletak pada pada suhu $100{ }^{\circ} \mathrm{C}$. Nilai Avrami eksponen ini sangat penting untuk menentukan bentuk pertumbuhan geopolimer. Kemudian untuk laju pertumbuhan kristal (K) paling cepat terjadi pada temperatur $80{ }^{\circ} \mathrm{C}$. Menurut Lukman et al, (2008) bila nilai $\mathrm{n}=1$, menunjukkan pertumbuhan dari nukleus terjadi seketika, sedangkan nilai $\mathrm{n}=2-3$ pertumbuhan spherulit dan bentuk nukleasi sporadis. Nilai (n) antara 0,959 dan 2,529 menunjukkan pertumbuhan dalam nukleasi seketika (instantaneous) dan bentuk nukleasi pertumbuhan dua dimensi. Namun, untuk pertumbuhan geopolimer nilai eksponen yang diharapkan mulai dari 1 - 2 dalam bentuk dua dimensi. Hasil ini menunjukkan bahwa pertumbuhan bentuk geopolimer dapat dikatakan sebagai dua dimensi.

Dari hasil uji pelindian /leaching paving blok yang dilakukan proses perendaman di dalam air selama 28 hari, terlihat kadar logam $\mathrm{Cu}, \mathrm{Pb}$, dan $\mathrm{Cd}$ mengalami leaching di dalam air kecuali logam $\mathrm{Cr}$ yang tidak terdeteksi.

Dari Tabel 2 di atas menunjukkan ratarata kadar logam $\mathrm{Cu}, \mathrm{Pb}, \mathrm{Cr}$, dan $\mathrm{Cd}$ sebelum solidifikasi dibandingkan setelah solidifikasi cukup jauh berkurang kadar logam berat mencapai $80 \%$ dan dilanjutkan uji leaching perendaman selama 28 hari kadar logam berat yang terlarut (leaching) masih dibawah batas maksimum, hal ini menunjukkan logam berat terimobilisasi baik dalam paving blok.

Kadar logam $\mathrm{Cu}$ dan $\mathrm{Pb}$ setelah pelindian selama 28 hari masing-masing sebesar 0,042 $\mathrm{mg} / \mathrm{L}$ dan $0,76 \mathrm{mg} / \mathrm{L}$ masih di bawah baku mutu maksimum kelas IV yaitu $0,2 \mathrm{mg} / \mathrm{L}$ untuk $\mathrm{Cu}$ dan 1,0 mg/L untuk Pb menurut PP No.82/2001, demikian juga kadar logam $\mathrm{Cr}$ tidak terdeteksi kemungkinan terikat sangat kuat dalam paving blok. Logam Kadmium (Cd) sebesar 0,072 $\mathrm{mg} / \mathrm{L}$ setelah 28 hari melebihi batas maksimum $0,01 \mathrm{mg} / \mathrm{L}$ kadar logam berat menurut PP No.82/2001 ini disebabkan logam berat tersebut terakumulasi dengan bertambahnya waktu perendaman akan tetapi bila dilihat kadar logam berat selama 6 hari pertama atau satu minggu pertama pada Tabel 3 masih sama dengan ambang batas menurut PP No. 82/2001. Dari hasil uji pelindian secara keseluruhan kadar logam berat dalam paving blok sudah terimobilisasi dengan baik sehingga paving blok aman dimanfaatkan bagi manusia dan lingkungan.

\section{SIMPULAN}

Dari hasil dan pembahasan yang telah dijelaskan dapat disimpulkan paving blok geopolimer yang dihasilkan adalah ;

1. Konstanta kinetika reaksi pertumbuhan partikel (K) tertinggi dengan nilai 4,75 x $10-^{2}$ dan nilai ekponen avrami $\mathrm{n}=2,310$ diperoleh pada temperatur optimum $80^{\circ} \mathrm{C}$. Rentang nilai Avrami's Eksponen untuk semua sampel antara 0,959 sampai 2,529 dengan demikian dapat disimpulkan bahwa bentuk pertumbuhan geopolimer memiliki struktur disc 2 dimensi.

2. Hasil uji pelindian paving blok sampel M16 yang optimum didapat kadar logam $\mathrm{Cu}, \mathrm{Pb}$, $\mathrm{Cr}$ dan $\mathrm{Cd}$ terikat kuat dalam paving blok ditunjukkan dengan kadar logam yang terlindikan masih dibawah ambang batas maksimum PP No.82/2001.

\section{UCAPAN TERIMA KASIH}

Terimakasih saya ucapkan kepada Tuhan Yang Maha Esa atas berkat yang diberikan kepada saya. Terimakasih kepada semua pihak yang telah banyak membantu baik material maupun non material demi mendukung saya dalam penelitian ini

\section{DAFTAR PUSTAKA}

physical and structural characterisation of geopolymer matrixes synthesized from coal (co-) combustion fly ashes, J.Hazard Matter Vol.154 page 175-183.

Bakharev, Tatiana. 2006. Thermal behavior of geopolymers prepared using class F-fly ash and elevated temperature curing, Cement and Concrete Research, 36(6), 1134-1147.

Mishra, A. and Choudhary. 2000. Effect of concentration alkalyn liquid and curing time on strength and water absorption of geopolymer concrete, ARPN Journal of Engineering and Applied sciences Vol.3 no. 1 p.87-93. 
Muniz , Bergna J . 2011. The effect of temperature on the geopolymerization process of a metakaolin-based geopolymer. Materials Letters, 65(6),995-998.

Olivia, M.,Putri., Damayanti. 2014. Parametric Study on the compressive strength of Palm Oil Fuel Ash (POFA) Geopolymer mortar. The International Conference on Enviromentally Friendly Civil Engineering Construction and Material, Manado Indonesia.
Revathi , Jayapanda, T. 2014. A Prospective study on alkali activated bottom ashggbs blend in paver block. International Journal of Civil, 